\section{Cureus}

Received 01/14/2019

Review began 01/25/2019

Review ended 02/01/2019

Published 02/08/2019

\section{(c) Copyright 2019}

Elfert et al. This is an open access article distributed under the terms of the Creative Commons Attribution License CC-BY 3.0., which permits unrestricted use, distribution, and reproduction in any medium, provided the original author and source are credited.

\title{
Chikungunya Virus Infection-related Rhabdomyolysis: A Case Report
}

\author{
Khaled Abdelmaqsoud Elfert ${ }^{1}$, Mohammed Abdelwahed ${ }^{2}$, Gerald Chi ${ }^{3}$ \\ 1. Internal Medicine, Hamad Medical Corporation, Doha, QAT 2. Pathology, Boston University Medical \\ Center, Boston, USA 3. Internal Medicine, Beth Israel Deaconess Medical Center, Boston, USA
}

$\square$ Corresponding author: Khaled Abdelmaqsoud Elfert, kh.elfert90@gmail.com

Disclosures can be found in Additional Information at the end of the article

\section{Abstract}

Chikungunya virus infection is an infection transmitted by mosquitoes. It classically presents with fever and arthralgia. The rhabdomyolysis as a complication of this infection is rarely reported in the literature. We report a case of a previously healthy 34-year-old male patient with acute onset of fever, myalgia, arthralgia, and dark colored urine. Laboratory values revealed elevated creatinine, positive urine dipstick for blood, but urine microscopy showed no red blood cells. Serum creatine kinase (CK) was elevated (>2000 U/L). Serology was positive for Chikungunya IgM antibodies. Rhabdomyolysis due to acute Chikungunya viral infection was diagnosed. Patient condition improved with supportive treatment and was discharged home.

Categories: Internal Medicine, Infectious Disease

Keywords: chikungunya, rhabdomyolysis, virology

\section{Introduction}

Chikungunya virus is transmitted by the Aedes aegypti and albopictus, a mosquito species widely distributed in Asia, Europe, Africa, and America. Dengue and Zika viruses are transmitted by the same mosquito vectors as Chikungunya, and coinfections have been documented. Clinical manifestations include abrupt onset of fever, malaise, arthralgia, headache, and gastrointestinal manifestations. Few cases showed no symptoms [1-2].

Rhabdomyolysis is a rare complication of Chikungunya virus infection and only few reports are available about Chikungunya virus infection-related rhabdomyolysis [3-6]. In an outbreak of Chikungunya virus infection, one patient developed acute exacerbation of pre-existing heart failure, rhabdomyolysis, and multiple organ failure [3].

We report a case of Chikungunya virus infection resulting in rhabdomyolysis in an otherwise healthy patient with no pre-existing medical conditions.

\section{Case Presentation}

A 34-year-old Indian male patient presented with two days history of fever, myalgia, and arthralgia mainly in the shoulders, hips, and hands. The patient had travelled from India to Qatar six days prior to presenting to the hospital. He also complained of diarrhea (five watery stools per day) and dark colored urine. He had no history of sick contacts but reported mosquito exposure in India.

Review of systems revealed productive cough and eye redness, otherwise, it was unremarkable. 


\section{Cureus}

On initial examination, his oral temperature was $39.4^{\circ} \mathrm{C}$, and blood pressure was $90 / 40 \mathrm{mmHg}$. There was conjunctival injection, and muscle tenderness in the shoulders and thigh muscles, but otherwise, the examination was normal.

The patient was resuscitated with five liters of normal saline and then blood pressure normalized.

\section{Investigations}

Laboratory investigations showed the following (Table 1):

\section{On admission \\ After four days}

$13.1 \mathrm{~g} / \mathrm{dL}$

$7.4 \times 10^{3} / \mu \mathrm{L}$

$6.2 \times 10^{3} / \mathrm{uL}$

$0.9 \times 10^{3} / \mathrm{uL}$

$137 \times 10^{3} / \mu \mathrm{L}$

$7.1 \mathrm{mmol} / \mathrm{L}$

$217 \mu \mathrm{mol} / \mathrm{L}$

$1.93 \mathrm{mmol} / \mathrm{L}$

$>2000 \mathrm{U} / \mathrm{L}$

$13.9 \mathrm{~g} / \mathrm{dL}$

$1.4 \times 10^{3} / \mu \mathrm{L}$

$0.5 \times 10^{3} / \mathrm{uL}$

$0.7 \times 10^{3} / \mathrm{uL}$

$62 \times 10^{3} / \mu \mathrm{L}$

$2.5 \mathrm{mmol} / \mathrm{l}$

$70 \mu \mathrm{mol} / \mathrm{L}$
$70-115 \mu \mathrm{mol} / \mathrm{L}$

2.1-2.6 $\mathrm{mmol} / \mathrm{L}$

39-308 U/L

\section{TABLE 1: Laboratory investigations.}

This table shows the initial investigations and after four days of admission.

N.B. His creatinine improved with fluid resuscitation.

He had 3+ blood in the urine dipstick but urine microscopic analysis revealed no red blood cells.

\section{Differential diagnosis}

The initial differential diagnosis included viral infection (e.g., including influenza, Dengue fever, Chikungunya virus infection) and parasitic infection (e.g., malaria). Bacterial infection was thought to be less likely because of lack of a focus of infection and symptoms (e.g., myalgias, arthralgias) pointing more towards a viral etiology.

Serologies for hepatitis C virus, hepatitis B virus, human immunodeficiency virus, and 


\section{Cureus}

parvovirus; and serum polymerase chain reaction (PCR) for Epstein-Barr virus, cytomegalovirus, and adenovirus were negative. Blood smears for malarial parasites were negative. Dengue virus IgG was positive. However, IgM antibody was negative, suggesting past infection. Additionally, nasal swabs were sent for influenza, parainfluenza, corona viruses PCR and were all negative. Two sets of blood cultures came negative.

Blood for Chikungunya IgM antibody test came positive, while IgG antibody test was negative suggesting acute infection (Figure 1) [1].

\begin{tabular}{||ll}
\hline Dengue Virus IgG & * A Positive \\
Dengue Virus IgM & * Negative \\
Hepatitis B Core Ab & Negative \\
Hepatitis B Surface Ab & Negative \\
Hep Bs Ab Num & * 0.00 \\
Hepatitis B Surface Antigen & Negative \\
Hepatitis C Ab & Negative \\
HIV Ag/Ab Combo & Negative \\
Adenovirus Qual & Negative \\
CMV PCR Qual & * Negative \\
EBV PCR Qual & Negative \\
Chikungunya Virus IgG & * Negative \\
Chikungunya Virus IgM & * A Positive
\end{tabular}

\section{FIGURE 1: The viral panel.}

This image shows the viral panel which was sent for the patient. It shows that IgM for Chikungunya and IgG for dengue were positive.

\section{Treatment}

The patient was given supportive treatment, and over his hospital stay, his symptoms improved and the laboratory abnormalities started to improve. He was discharged to home after six days.

\section{Discussion}

We present a case of Chikungunya virus infection complicated by rhabdomyolysis, a rare complication of the infection. The patient recovered uneventfully with conservative management and was discharged to home.

The most common presenting features reported in the literature are fever (92\%) which varies from low grade to high grade, and arthralgia (87\%) which can occur without a fever. The joint pain is usually worse in the morning. It is relieved by mild exercise and aggravated by aggressive movements. Headache and chills occur in $62 \%$ of patients [7]. The diagnosis of Chikungunya fever is confirmed using real-time reverse-transcription polymerase chain reaction (RT-PCR) or Chikungunya virus serology [1].

Rhabdomyolysis is diagnosed in a patient with either an acute neuromuscular disease or dark urine without other symptoms when creatine kinase (CK) is markedly elevated. That elevation is typically five times the upper limit of normal and is usually above $5000 \mathrm{U} / \mathrm{L}$ [8]. So, usually, the patient will present with the classic triad of myalgias, generalized weakness, and darkened urine. On the other hand, asymptomatic serum CK elevation occurs with no or insignificant muscle-related signs and symptoms. In our case, the patient had myalgia and dark colored 
urine. In addition, he had a CK level of more than $2000 \mathrm{Ul} / \mathrm{L}$, but we could not get the exact number as the Analytical Measuring Range of the analyzer was verified up to $2000 \mathrm{U} / \mathrm{L}$ only. The patient was not taking any medications prior to his current illness. He denied alcohol intake. He had no recent seizure episode or trauma. So, there was no other possible etiology to explain the rhabdomyolysis.

Our literature search revealed a reported case of culture-confirmed Chikungunya virus infection-associated death in a patient who developed an acute exacerbation of pre-existing heart failure, rhabdomyolysis [3]. In another case report, a patient infected with Chikungunya virus developed rhabdomyolysis complicated by renal failure requiring dialysis [5]. In Suriname, during an outbreak of Chikungunya virus infection, a case of an 11-year old patient who presented with fever, myalgia, and dark colored urine was diagnosed with Chikungunya complicated with rhabdomyolysis due to viral myositis [6]. In one outbreak on Reunion Island, 15 out of the 157 infected patients had a CK level of more than $1000 \mathrm{U} / \mathrm{L}$ [9]. However, it is unclear how many of these patients had rhabdomyolysis vs. asymptomatic elevation of CK, as no patients were labeled as having rhabdomyolysis in this study and all we have are the laboratory values of the studied subjects. Two cross-sectional studies of outbreaks occurred in Malaysia and Southern Mexico did not report CK values for patients with Chikungunya virus infection [10-11]. A recent cross-sectional study, published in December 2018, studied the outbreak which occurred in French Guiana between February 2014 and October 2015; it showed that three patients out of the study population $(n=285)$ developed rhabdomyolysis [12].

Following the outbreak of Chikungunya virus in La Reunion islands in 2005, a number of studies started discussing the role of viral infection in affecting muscle tissues, causing rhabdomyolysis. A recent study discussed the role of attacking muscle satellite cells in the incidence of rhabdomyolysis. According to the study published by Ozden et al. [4], "Immunohistology on muscle biopsies from two Chikungunnya virus-infected patients with myositic syndrome showed that viral antigens were found exclusively inside skeletal muscle progenitor cells (designated as satellite cells), and not in muscle fibers." Satellite cells are myogenic precursor cells that persist in postnatal and adult muscle. Also in vitro studies showed that the Chikungunya virus has the ability to replicate inside human satellite cells with cytopathic effect, while it is not growing inside the myotubes [4].

Regarding the hematological abnormalities, our patient developed neutropenia, lymphopenia, and thrombocytopenia. During an outbreak of Chikungunya infection in Malaysia, lymphopenia and neutropenia (counts $<1 \times 103$ cells $/ \mathrm{mm} 3$ ) were seen in two-thirds of presenting patients during their admission to the hospital $(n=117)$ with median lymphocyte and neutrophil count of $0.8 \times 103 / \mathrm{uL}$ and $0.9 \times 103 / \mathrm{uL}$ cells $/ \mathrm{mm}^{3}$, respectively. Thrombocytopenia were seen in $89 \%$ of patients (platelets $<150,000$ cells $/ \mathrm{mm} 3$ ) [10].

Blood chemistry for our patient showed he has hypocalcemia. Hypocalcemia is a laboratory abnormality known in patients with Chikungunya virus infection [11]. In an outbreak of Chikungunya on Reunion Island, hypocalcemia (blood calcium level, $<2.25 \mathrm{mmol} / \mathrm{L}$ ) was present in 86 patients out of 157 [9]. Hypocalcemia in rhabdomyolysis usually occurs in the first few days and is most likely attributed to the deposition of calcium in injured tissues [13]. As the hypocalcemia in Chikungunya virus infection is fairly common, while rhabdomyolysis is a rare complication of the infection, there could be other possible mechanisms for hypocalcemia other than muscle injury and rhabdomyolysis.

Regarding treatment of the acute phase, there is no specific antiviral therapy for acute Chikungunya virus infection. Treatment during the acute phase of the disease is symptomatic for fever and pain using nonsteroidal anti-inflammatory drugs. Systemic glucocorticoids and other immunosuppressive medications are better to be avoided in patients during acute 
infection [14].

\section{Conclusions}

Physicians should be aware that rhabdomyolysis could be a part of Chikungunya virus infection presentation, which necessitates early and aggressive fluid resuscitation.

\section{Additional Information Disclosures}

Human subjects: Consent was obtained by all participants in this study. Conflicts of interest: In compliance with the ICMJE uniform disclosure form, all authors declare the following: Payment/services info: All authors have declared that no financial support was received from any organization for the submitted work. Financial relationships: All authors have declared that they have no financial relationships at present or within the previous three years with any organizations that might have an interest in the submitted work. Other relationships: All authors have declared that there are no other relationships or activities that could appear to have influenced the submitted work.

\section{Acknowledgements}

I would like to express the deepest appreciation to Professor Adeel Butt for his guidance and expert advice.

\section{References}

1. Weaver SC, Lecuit M: Chikungunya virus and the global spread of a mosquito-borne disease . N Engl J Med. 2015, 372:1231-1239. Accessed: July 12, 2018: http://www.nejm.org/doi/10.1056/NEJMra1406035. 10.1056/NEJMra1406035

2. Hochedez P, Jaureguiberry S, Debruyne M, et al.: Chikungunya infection in travelers. Emerg Infect Dis. 2006, 12:1565-1567.

3. Sam IC, Kamarulzaman A, Ong GSY, et al.: Chikungunya virus-associated death in Malaysia . Trop Biomed. 2010, 27:343-347. Accessed: July 12, 2018: http://wwwnc.cdc.gov/eid/article/12/10/06-0495_article.htm.

4. Ozden S, Huerre M, Riviere J-P, et al.: Human muscle satellite cells as targets of Chikungunya virus infection. PLoS One. 2007, 2:e527. Accessed: April 13, 2018: https://www.ncbi.nlm.nih.gov/pmc/articles/PMC1885285/. 10.1371/journal.pone.0000527

5. Hamid A, F. Dhrolia M, Qureshi R, Imtiaz S, Ahmad A: Acute kidney injury secondary to rhabdomyolysis: a rare presentation of Chikungunya fever. J Coll Phys Surg Pak. 2018, 28:S94S96. Accessed: January 19, 2019 : http://www.ncbi.nlm.nih.gov/pubmed/29866233.

6. van ’t Kruys K, Zonneveld R, Liesdek S, Zijlmans W: Rhabdomyolysis in children: three exotic presentations from Suriname. J Trop Pediatr. 2018, Accessed: January 19, 2019 : https://academic.oup.com/tropej/advance-article/doi/10.1093/tropej/fmy043/5061535. 10.1093/tropej/fmy043

7. WHO, Searo: Guidelines on Clinical Management of Chikungunya Fever. WHO Regional Office for South-East Asia, 2008.

8. Melli G, Chaudhry V, Cornblath DR: Rhabdomyolysis: an evaluation of 475 hospitalized patients. Medicine (Baltimore). 2005, 84:377-385. Accessed: July 13, 2018: http://www.ncbi.nlm.nih.gov/pubmed/16267412. 10.1097/01.md.0000188565.48918.41

9. Borgherini G, Poubeau P, Staikowsky F, et al.: Outbreak of Chikungunya on Reunion Island: early clinical and laboratory features in 157 adult patients. Clin Infect Dis. 2007, 44:14011407. Accessed: July 14, 2018: https://academic.oup.com/cid/article/44/11/1401/475984. $10.1086 / 517537$

10. Chew LP, Chua HH: Outbreak of Chikungunya in Johor Bahru, Malaysia: clinical and laboratory features of hospitalized patients. Med J Malaysia. 2009, 64:220-222. Accessed: January 12, 2019 : http://www.ncbi.nlm.nih.gov/pubmed/20527272. 


\section{Cureus}

11. Danis-Lozano R, Díaz-González EE, Trujillo-Murillo K del C, et al.: Clinical characterization of acute and convalescent illness of confirmed chikungunya cases from Chiapas, S. Mexico: a cross sectional study. PLoS One. 2017, 12:Accessed: April 13, 2018:

https://www.ncbi.nlm.nih.gov/pmc/articles/PMC5655440/. 10.1371/journal.pone.0186923

12. Bonifay T, Prince C, Neyra C, et al.: Atypical and severe manifestations of Chikungunya virus infection in French Guiana: a hospital-based study. PLoS One. 2018, 13:e0207406. Accessed: January 19, 2019: http://dx.plos.org/10.1371/journal.pone.0207406.

10.1371/journal.pone.0207406

13. Akmal M, Bishop JE, Telfer N, Norman AW, Massry SG: Hypocalcemia and hypercalcemia in patients with rhabdomyolysis with and without acute renal failure. Clin Endocrinol Metab. 1986, 63:137-142. Accessed: July 13, 2018: https://academic.oup.com/jcem/articlelookup/doi/10.1210/jcem-63-1-137. 10.1210/jcem-63-1-137

14. Simon F, Javelle E, Cabie A, et al.: French guidelines for the management of chikungunya (acute and persistent presentations). Médecine Mal Infect. 2014, 45:243-263. Accessed: July 13, 2018: https://www.sciencedirect.com/science/article/pii/S0399077X15001444? via\%3Dihub. 10.1016/J.MEDMAL.2015.05.007 